\title{
Escapismo de sí mismo: Medardo Ángel Silva como poeta marginal y la autonegación de la identidad.
}

\section{Resumen}

Este ensayo explora nuevas perspectivas críticas sobre la obra del poeta modernista ecuatoriano Medardo Ángel Silva, enfatizando aspectos previamente invisibilizados como su ascendencia africana y su baja extracción social. Con esto, se relaciona el carácter contradictorio y "escapista" de la poesía de Silva con su identidad autonegada de sujeto marginal, para encontrar interpretaciones de su sensibilidad sin necesidad de recurrir a un Zeitgeist modernista o a un modelo de importación estética. En dos poemas selectos, se buscan y se detectan los rastros de la contradicción esencial y de la autonegación que hacen del poeta ecuatoriano un autor propiamente modernista.

Palabras claves

Medardo Ángel Silva, modernismo, Ecuador, poesía, identidad.

\begin{abstract}
This essay explores new critical perspectives on the work of the Ecuadorian poet Medardo Ángel Silva. Previously ignored aspects, such as his race and his low-class social status, are emphasized. The contradictory and "escapist" character of Silva's poetry is linked to his own self-denied identity as a marginal subject, in order to find interpretations to his sensibilities that do not invoke an uncertain Zeitgeist or a model of aesthetic importation. In two poems, traces of this essential contradiction and of this self-denial are searched for and found, leading to a new comprehension of Silva's work within the canon of modernismo.
\end{abstract}

Keywords

Medardo Ángel Silva, modernismo, Ecuador, poetry, identity. 
En el contexto de la lírica ecuatoriana, es probable que no haya poeta más leído que el guayaquileño Medardo Ángel Silva (1898-1919), y sin lugar a dudas no hay ninguno tan superficialmente conocido y a la vez profundamente querido a nivel popular. "Superficialmente conocido" porque su nombre y hasta ciertos detalles de su biografía son referentes compartidos por buena parte de la población ecuatoriana, y muy especialmente guayaquileña, mucho más allá de la ciudad letrada. "Profundamente querido" porque, a más tardar desde la interpretación musical en forma de pasillo de su poema "El alma en los labios" por parte de Julio Jaramillo, la historia de sus "amores imposibles" y de su "misterioso" suicidio han pasado a ser ejemplos "concretos" y altamente significativos, en el imaginario popular, de lo que implica la experiencia de la guayaquileñidad o de la ecuatorianidad.

No obstante, y quizás paradójicamente, Silva es también uno de los autores peor leídos de la historia del Ecuador, si no el peor leído de todos. De hecho, en esto la recepción de la obra del "niño poeta de Guayaquil" (Balseca 2004: 13) no sólo es representativa de la de la obra poética de toda su generación, la así llamada "generación decapitada" de jóvenes escritores ecuatorianos habitualmente reconocidos por la crítica como magistrales en todo lo que respecta a la técnica pero que, tradicionalmente, "ha[n] sido desvalorizado[s] aduciendo su asincronía, su encapsulamiento, [y su] excepcionalidad" (Manzoni 19), sino que también es representativa de la lectura que, durante décadas, se ha realizado de la obra de gran parte de los miembros del movimiento modernista hispanoamericano en general, en cuyas coordenadas estéticas y temporales se inscribe la obra de Silva.

${ }^{1}$ Estrictamente, los integrantes de la "generación decapitada" son nada más Arturo Borja, Humberto Fierro, Ernesto Noboa Caamaño y Medardo Ángel Silva, fallecidos todos a edades más o menos tempranas y en circunstancias más o menos suicidas. Campaña Avilés, sin embargo, aboga por abrir la categoría y considerar como "decapitados" a otros poetas de la época, en vista de que el concepto de "decapitado" ha pasado básicamente a significar, en el Ecuador, exactamente lo mismo que "modernista" (10). 
En efecto, tanto Silva como los decapitados como el modernismo han sido celebrados como cúspides de la creación y de la innovación poética en un plano puramente formal, de l'art pour l'art, pero al mismo tiempo también repetidamente condenados por su cosmopolitismo europeizante y supuestamente reaccionario, por su "escapismo" y por su supuesta negación a confrontar la "realidad", es decir por lo en última instancia —y según esta interpretaciónmasturbatorio de ese mismo art pour l'art. Como no podía ser de otra manera, la condena pesa más.

Así, varios respetados comentaristas de la cultura ecuatoriana han escrito de la generación de Silva que "todo lo ofrendó en el altar de las drogas, las melenas, los demonios trocados en princesas de acres emanaciones perfumadas, $\mathrm{y}$ los ánades vulgares vueltos cisnes, cuyo cuello, en verdad, nadie fué [sic] capaz de torcer" (Pareja Diezcanseco XVII); que era "reaccionaria en lo social, renovadora en lo estético [y hacía] de la poesía un vehículo para expresar su disconformidad con el ambiente 'municipal y espeso' creado por la revolución liberal; vale decir, su desadaptación en una sociedad donde el aristócrata ha dejado de ser amo y señor absoluto" (Cueva 48); y que, "[a]nte el hastío que les causaba la falta de correspondencia entre las evocaciones palatinas, las formas refinadas y cultas, y los contenidos utilitaristas y 'vulgares', estos poetas decidieron evadirse, primero con el opio y después con la misma muerte" (Fernández 32).

Para poner un ejemplo proveniente del discurso literario y no de la crítica, en la novela Pájara la memoria (1985), de Iván Egüez, el narrador se refiere de manera no muy velada a los decapitados de la siguiente manera: "El hijo de Dolores, el Niño del Prado, murió de pena cuando le comunicamos que había de abandonar los Soles Negros, se suicidó repitiendo 'Prefiero morir aquí, levantar el cuello junto a mis cisnes, en el estanque de aguas estigias, aquí está la tumba que merezco" (109-10). Por último, e incluso en fechas tan relativamente recientes como 1995, Gilda Holst resume la tradición crítica sobre el capítulo ecuatoriano del modernismo con estas bastante lapidarias palabras: "A pesar de su extracción 
social, [...] Silva, igual que sus compañeros modernistas, se refugia en la nostalgia de un pasado aristocratizante frente a la 'vulgaridad' de los estratos medios que emergían de manera incipiente. [...] Sin embargo, la calidad de la poesía de Silva no puede ponerse en duda” (Holst 4482, énfasis mío).

\section{Nuevas lecturas de Silva: Balseca, Benavides y Vallejo}

Por supuesto, en los últimos años esta valoración tradicional del modernismo ecuatoriano, que con más o menos matices es extensible a la del modernismo hispanoamericano en general, ha empezado a ser repensada, sobre todo en los tanto en envergadura como en metodología muy distintos trabajos que sobre Silva han realizado Fernando Balseca (2004, 2009), O. Hugo Benavides (2006) y Raúl Vallejo (2004). El primero de ellos inserta, en Llenaba todo de poesía, la obra de Silva en el contexto de la "nueva" lectura del modernismo como movimiento contradictorio y como profunda (y originaria) ruptura cultural en América Latina, más allá de los clichés del afrancesamiento, del torremarfilismo y del escapismo (Paz; Pacheco; González; etc.). Además, Balseca demuestra que, lejos de haber sido llevada a cabo de espaldas a la "realidad", la poesía de Silva está íntimamente ligada a procesos históricos y sociales concretos (en este caso, al empeño consciente de una burguesía emergente por imponer una renovación política, urbana y aun literaria [53-54]), así como a una topografía cultural específica del tiempo y del lugar en los que al autor le tocó vivir, y que incluye instituciones educativas y publicaciones periódicas (58-75).

Preocupado por los mecanismos que han permitido integrar la obra y la biografía/leyenda de Silva en el imaginario colectivo de la guayaquileñidad, por su parte, Benavides enfatiza la posición marginal del poeta dentro de su propia sociedad (factor mencionado por Holst sólo de paso, y sólo para ser inmediatamente descartado, en la cita de más arriba), en su calidad de individuo pobre y, para colmo de males (en el contexto específico del que se habla), de piel oscura. En este sentido, y como sujeto periférico dentro de la periferia, Silva no 
sólo no era escapista, para Benavides, sino que "[was] clearly concerned with social conventions and hierarchies. [He] was deeply troubled by both the darkness of his skin and his quite limited socioeconomic standing” (21). Por la vía de la negación de eso que para todos los demás era "evidente", entonces, y de la articulación poética de dicha negación, Silva "was single-handedly able to register an enormous level of discomfort and misrepresentation of what it felt to be Guayaquilean during his lifetime" (144).

En su ingeniosamente titulado artículo "Medardo Ángel Silva y la crónica de una época de artificios", finalmente, Vallejo destaca la relevancia de las hasta hace poco más o menos ignoradas crónicas de Silva, muy en concordancia con una tendencia más amplia de romper con la comprensión reduccionista del modernismo hispanoamericano como movimiento casi exclusivamente lírico (Rotker; Jiménez y Morales; González). Este enfoque le permite a Vallejo concluir, después de un sucinto "análisis descriptivo" (468), que "la crónica le dio [a Silva] — por encima de su propia conciencia- el vehículo para expresar directamente el horror de un modelo económico $-\mathrm{y}$ sus representaciones ideológicas - en el que todo lo sólido se había desvanecido en el aire" (480).

Partiendo de las conclusiones de estos tres trabajos, y tomándolas como premisas, en las siguientes páginas se leerán dos textos silvianos concretos para establecer en ellos las huellas de la autonegación identitaria y de las contradicciones que explican el así llamado escapismo del autor guayaquileño, de forma que se haga posible una relectura de dicho escapismo como comentario ciertamente revelador sobre la "realidad" de la modernidad. Antes de proceder a este análisis, sin embargo, es necesario abrir más el obturador, en un primer paso, para trazar aunque sea un esbozo de una teoría estética del modernismo como movimiento y así poder, una vez establecidos algunos de sus parámetros, insertar a Silva en éste. 


\section{Hacia una contextualización del modernismo como lugar de conflicto}

Mucho más aún que de otros movimientos literarios, del modernismo se puede decir que no es una escuela poética unitaria y homogénea, sino más bien un espacio de confluencia de diferentes elementos diferentes y hasta contrapuestos. De hecho, es posible acercarse al modernismo por medio del análisis de las tensiones inherentes a algunas de sus contradicciones fundamentales. Así, por ejemplo, a lo sin duda epígono y afrancesado de la poesía modernista se puede oponer su indiscutible ímpetu innovador y su fuerte anclaje en el castellano y en el universo hispánico; al casi proverbial escapismo y torremarfilismo de sus exponentes, el compromiso político de algunos de sus autores, pero también, aunque menos evidentemente (al menos a primera vista), el valor del movi-miento entero como documento del shock ante la modernidad de más de una generación ${ }^{2}$; al aparentemente desmedido interés por los cisnes, las ninfas y los jardines japoneses, la fundación consciente de una literatura por vez primera específicamente latinoamericana.

Este carácter dialéctico del modernismo, crisol de influencias diversas y sintetizador productivo de una nueva y original sensibilidad literaria, puede ser rastreado tanto en la obra poética como en su recepción crítica, ocupada ya desde hace décadas en bregar, con mayor o menor éxito, con lo contradictorio y finalmente inasible e inclasificable del movimiento. Reaccionaria, conservadora, progresista e incluso revolucionaria al mismo tiempo, la estética modernista es preciosista y etérea en extremo, pero es, también, la estética por antonomasia del doloroso parto de la modernidad en América Latina y, como tal, una estética indisolublemente entrelazada con el devenir histórico del subcontinente. Más aún, como estética de esta labor de parto, de este proceso social que incluye la

\footnotetext{
${ }^{2}$ Naturalmente, el concepto del shock en este contexto remite al ensayo benjaminiano Charles Baudelaire. Ein Lyriker im Zeitalter des Hochkapitalismus, y muy especialmente a su segunda parte "Über einige Motive bei Baudelaire", en el que se discute (entre otras) la cuestión de "wie lyrische Dichtung in einer Erfahrung fundiert sein könnte, der das Chockerlebnis zur Norm geworden ist" ("cómo la poesía lírica podría fundarse en una experiencia en la que la vivencia del shock se ha convertido en la norma" [Benjamin 614, mi traducción]).
} 
literatura y la desborda, el modernismo no es solamente un mero reflejo de la forzosa pero también orgánica inscripción de las repúblicas latino-americanas en la modernidad burguesa a finales del siglo XIX, sino además el código cultural, el lenguaje, con el que dicho parto se nombra, se hace inteligible y se constituye como un proceso fundacional complejo, enmarcado en un marco global y sujeto a múltiples vaivenes (que no un proceso de simple importación acrítica o de aculturación).

Para entender ciertos aspectos del modernismo como fenómeno cultural heterogéneo y dialéctico de y en una época de crisis, quizás sea útil recurrir a una versión "desdogmatizada" del concepto originalmente trotskista del desarrollo desigual y combinado supuestamente característico de los países coloniales y semicoloniales (o postcoloniales) ${ }^{3}$. Según esta teoría, lejos de ser esos lugares primitivos pasados de largo por la revolución industrial, y por lo tanto condenados a la explotación imperialista hasta la llegada del socialismo a tierras europeas y norteamericanas, los países coloniales y semicoloniales, por sus mismos vínculos (de dependencia) con un mercado ya irremediablemente global, son espacios en los que coexisten las tradiciones más claramente feudales o premodernas con lo vertiginoso del capitalismo moderno, y por extensión las estructuras de opresión más anquilosadas con las superestructuras más de avanzada y más favorables a la liberación.

Dejando de lado lo lamentablemente teleológico de este modelo eurocéntrico, cuyas consecuencias políticas son bastante evidentes ${ }^{4}$, es interesante su énfasis en lo múltiple, en lo simultáneo y en lo profundamente contradictorio de la experiencia de la modernidad capitalista en sociedades como las de América

\footnotetext{
${ }^{3}$ La teoría del desarrollo desigual y combinado, parte esencial del programa de la revolución permanente con el que el trotskismo quedó indisolublemente asociado a partir de los años veinte del siglo pasado, fue desarrollada por primera vez por Trotsky en su artículo "Resultados y perspectivas", redactado en 1906 como reflexión de los eventos de la revolución rusa de 1905.

${ }^{4}$ A saber: la revolución socialista, desde esta perspectiva, no es sólo posible sino probable (y, de hecho, históricamente inevitable) en los países coloniales y semicoloniales, incluso sin que éstos pasen por una etapa de producción propiamente capitalista y de una dominación propiamente burguesa.
} 
Latina durante la época de la irrupción del modernismo. En un contexto en el que están presentes al mismo tiempo las "masas mudas de indios" de Martí y las más sofisticadas innovaciones foráneas, y en el que el "impuro amor de las ciudades" de Casal se construye ya abiertamente como contrapunto, y como contrapunto implícita o explícitamente superior, de un todavía ubicuo campo abyecto (un campo no sólo rural sino ruralizado), los autores modernistas se enfrentan, por un lado, a la rápida desintegración de todo un universo y, por otro, a la promesa de un "desarrollo" que, sin embargo, es a todas luces, y ya para sus contemporáneos, "desigual y combinado". Ante el shock inicial de esa modernidad incompleta y rara, entonces, y a medio camino entre el pasado colonial y el supuesto futuro importado de Europa, el resultado no puede ser otro (por ahora: el mesianismo literario llegará después...) que una estética de la angustia y de la nostalgia por un ayer inexistente y mítico y por un mañana igualmente ficticio o al menos incierto; en otras palabras, de una estética anclada en un presente cambiante, que se mueve, que no para, y cuyo principio es la fragmentación y la contradicción: una estética contradictoria y rara.

De este modo, y para citar sólo unos pocos ejemplos, las estructuras polares de la poesía de Martí y Casal (Schulman 153-87) dejan de parecer ejercicios retóricos "puros" para pasar a ser formas de expresión de una modernidad polar (de hecho, multipolar). Asimismo, el oxímoron dariano de la imitación original se revela, más que como un mero juego de palabras - $-\mathrm{y}$ más que como una respuesta irónica a los críticos del afrancesamiento-, como un agudo comentario sobre las condiciones en las que se practica la literatura en un mundo mercantilizado y esencialmente cosmopolita. Finalmente, la corporalidad de Agustini, por no mencionar su propia biografía abrupta y escabrosamente truncada, así como su consiguiente imagen de "estrella literaria" (no siendo ella siquiera, ni remotamente, la única ni la más famosa "estrella" del modernismo), anuncia desplazamientos e incluso pequeñas fisuras en el patriarcado imperante, así como en las relaciones entre las esferas de la literatura y de la naciente cultura 
popular (pienso en el star system), y deja de ser una anomalía atribuible exclusivamente a patologías mentales o a una ahistórica écriture féminine.

Para resumir, entonces, es posible decir que el modernismo es el lugar de confluencia, y de conflicto, de elementos y estímulos diversos y contradictorios, pero también que la estética modernista tiene lugar en los espacios variables que existen entre esos estímulos, en los intersticios y entre los polos en constante tensión, en un presente - un presente propiamente moderno - atrapado entre la nostalgia por un pasado ficticio y el deseo de un futuro incierto. Una expresión plena, y plenamente consciente, en otras palabras, del desafío de la modernidad.

\section{La irrupción de nuevos actores: Silva como sujeto marginal en la periferia}

Acaso la mención de la poesía de Agustini más arriba sea la más relevante a la hora de intentar dibujar la figura de un Silva modernista dentro de un concepto del modernismo como espacio de conflicto. Por un lado, el fin trágico de ambos los emparenta ${ }^{5}$, del mismo modo que las respectivas leyendas que se han configurado alrededor de los (supuestos) hechos de sus vidas y que han convertido a ambas figuras, como también ya se apuntó, en verdaderas estrellas literarias. Por otro lado, y de manera mucho más fundamental, si aceptamos que “el modernismo [es] el lugar donde podrán leerse tanto los intentos modernos de constituir una tradición y el auge de los nacionalismos literarios, [...] las defensas culturalistas, los cosmopolitismos, las reivindicaciones del egoísmo y del placer, o el nacimiento de la literatura social [...] la incorporación, en fin, de otros actores" (Lasarte Valcárcel 38), podemos leer no sólo a Agustini en clave de sujeto femenino que escribe desde la rabia y la marginalidad, sino también a Silva como un sujeto marginal y periférico incluso en la periferia (Balseca 2004: 18), en esa modernidad tan inevitablemente desigual y combinada.

\footnotetext{
${ }^{5}$ En este sentido, quizás una comparación con Alfonsina Storni sería todavía más pertinente, dado que la poetisa argentina se suicidó como, con una probabilidad rayana en la certeza, también lo hizo Silva.
} 
En efecto, en su condición de individuo de piel notablemente oscura en una sociedad racista y europeizante como la del Guayaquil de principios del siglo XX (es decir, en la ciudad más grande de un país en el que la necesidad y la conveniencia del "blanqueamiento" de la población constituye un mito fundacional [E. Silva 17-18]), y como persona de escasos recursos económicos en un puerto marítimo obsesionado con la acumulación de riquezas, Medardo Ángel Silva está, ya a nivel puramente corporal, doblemente marcado como outsider con respecto a las elites culturales de la época. Peor aún, su propio interés por la poesía lo condena, en un medio ultra-comercial y tradicionalmente hostil a las artes y a las letras ${ }^{6}$, a permanecer en la pobreza (al menos en la pobreza relativa). Por eso, un sujeto como Silva, en principio, no puede abrigar ni la menor esperanza de conseguir jamás el suficiente dinero como para poder adquirir una identidad "blanqueada" y acceder, por esa vía, a una posición social supuestamente más acorde a sus talentos y a sus anhelos, pero que le está vedada, precisamente, tanto por su clase social como por su aspecto físico.

El problema es, de hecho, irresoluble, pues en el entrecruzamiento de la raza, de la pertenencia a un estrato específico y de la sensibilidad artística de Silva se produce una identidad que, al igual que la raza en sí, o que la clase social, es "sólo" una construcción social, pero no por ello una menos real". Al fin y al cabo, se trata de una construcción social que es constante e interminablemente impuesta, como realidad, por el mismo entorno, y que es inscrita en el cuerpo

\footnotetext{
${ }^{6} \mathrm{Si}$ bien es cierto que, como ya se ha mencionado, Balseca (2009: 53-54) alude a un proceso de renovación no sólo político sino también cultural promovido por sectores de la emergente burguesía guayaquileña del período que aquí se trata, es innegable que esta tendencia constituye una más bien minoritaria, así como una que, en definitiva, no es capaz de romper con la tradición antiintelectual hegemónica de Guayaquil.

${ }^{7}$ El concepto de "construcción social" que se usa aquí es uno similar al que Judith Butler (1993) aplica a la categoría de "sex": “To 'concede' the undeniability of 'sex' [or race or class position] or its 'materiality' is always to concede some version of 'sex' [or race or class position], some formation of 'materiality'. Is the discourse in and through which that concession occurs -and, yes, that concession invariably does occur- not itself formative of the very phenomenon that it concedes? To claim that discourse is formative is not to claim that it originates, causes, or exhaustively composes that which it concedes; rather, it is to claim that there is no reference to a pure body which is not at the same time a further formation of that body. [...] The constative claim is always to some degree performative" (10-11).
} 
mismo del sujeto, de modo que delimita la situación de éste y su espacio para accionar.

No solamente la sociedad sabe que Silva es económica y racialmente "inferior", así, sino que el poeta mismo está, por supuesto, perfectamente consciente de estas limitaciones, así como de sus causas. Cuando, por ejemplo, durante una fiesta le es ofrecida, medio en serio medio en broma, la agregaduría cultural en París, "no se engañan ni él ni los que lo rodean: [...] no hay posibilidades de que incursione en dicha carrera [...] por el tono de su piel, que hace que Pino de Ycaza lo llame 'Apolo vaciado en ébano"' (Mussó 34). En lugar de conformarse con los designios de su medio, sin embargo, el guayaquileño opta (como por cierto también la casi totalidad de la crítica posterior) ${ }^{8}$ por la negación de su identidad y por la creación de una persona artificial que escribe su propio pasado y construye su propia agencia, por más frágil que ésta sea. Por ejemplo, en la que parece ser la única alusión explícita a su piel oscura escrita jamás por el poeta, Silva afirma lo siguiente:

I despair in poverty and I am offended by blackness. It is curious: I am a man of pure white race. My grandfather was Spanish. It is useless to explain a freak phenomenon of nature. But you must know that in me harbors a pure Iberian heritage. However, I look like a black Moor. And this physical reality, in my country, is a source of shame. But I would not mind as much being the black member of my family, if, [sic] in addition I also were not poor. This is what is most horrible. (citado en Benavides, 18 [su traducción] $)^{9}$

\footnotetext{
${ }^{8}$ Significativamente, el recién citado Mussó, en fechas tan recientes como el año 2004, y no obstante su conciencia del "tono de piel" de Silva, repite el mito de la procedencia directamente española del poeta ecuatoriano por vía de su abuelo paterno (29), cuya base histórica es tan exigua que, ahora, incluso un texto de divulgación como el de Simón Espinosa, orientado a estudiantes colegiales, lo descarta de plano (36).

${ }^{9}$ El texto original, proveniente de una carta personal del poeta, está recogido en la única biografía que de Silva se ha escrito hasta la fecha, la de Abel Romeo Castillo (a quien Benavides insiste en llamar, incorrectamente, Abel Romero Castillo) de 1970, que lamentablemente no estaba a mi disposición durante la redacción de este ensayo.
} 
La autonegación articulada en este pasaje es evidente, y bastaría, a primera vista, para hacer de Silva un personaje efectivamente escapista y delirante, ajeno a la más elemental realidad. No obstante, hay algo en el tono exagerado de esta autonegación que apunta hacia otras tensiones inherentes. Querer detectar una fuerte carga irónica en expresiones como "pure Iberian heritage" y "freak phenomenon of nature" sería, quizás, una interpretación excesiva, y sin duda demasiado favorable al autor ecuatoriano, pero lo cierto es que el texto, por su misma repetición aparentemente innecesaria de la pureza racial de su autor, puede ser leído como un aspaviento performativo provocado por la angustia ante un orden específico y ante la imposibilidad estructural de cambiarlo. Lejos de cerrar los ojos ante una realidad que lo reduce a sujeto periférico en la periferia desigual y combinada que es el Guayaquil del siglo XX, entonces, Silva acomete aquí, en clara relación con el mundo exterior y con un nada velado deseo de influir en éste por medio de la escritura, una identidad propia que pasa, necesariamente, por la negación de su propia identidad "real".

\section{Elementos de autonegación por vía del silencio en la poesía de Silva}

La autonegación que en el fragmento citado arriba se hace explícita está, por su parte, sólo implícita en la obra poética de Silva, en la que cualquier mención a la propia marginalidad del autor está ausente. El poeta, que repetidamente se presenta como una especie de libro abierto en todo lo relacionado con sus "divagaciones sentimentales" (para aludir al título de una de las secciones de su primer y más famoso poemario, El árbol del Bien y del Mal [1918]) y con la "amargura" que le causa el "dejar de ser niño / y empezar a ser hombre" ("Aniversario" [Silva 305-07]), guarda un completo silencio no sólo sobre las luchas políticas y sociales de su tiempo (marcado como está éste por la Revolución Liberal y la emergencia del movimiento obrero en el Ecuador), como la crítica tradicional le ha echado consistentemente en cara, sino también sobre su 
extracción social y sobre sus características raciales, así como sobre la angustia que éstas le provocan. Si leemos a Silva como un sujeto marginal que construye una persona artificial y reescribe su propia identidad para contraponerla a la en su opinión mediocre paleta de posibilidades que le ofrece su medio, sin embargo, y consideramos también que su rol de héroe romántico en la flor de la juventud pero subjetivamente decrépito es, también, una persona artificial, este silencio puede dejar de ser interpretado como un escape en el sentido peyorativo de la palabra. De hecho, más bien puede ser visto como parte de la estrategia silviana de autoconstrucción textual como autor "objetivamente" marginal y que, sin embargo, por medio de la palabra, y en este caso también de su silencio, logra inscribirse en un contexto que, como el contexto de la producción cultural ecuatoriana de principios del siglo XX, excluye implacablemente a los sujetos marginales.

Además, el silencio de Silva dice algo. Consideremos, por ejemplo, el tercer poema de sus ya mencionadas "Divagaciones sentimentales":

Princesa de los ojos floridos y románticos

que vierten suave luz purificadora,

por quien deshojo todos los lirios de mis cánticos

y hay en mis negras noches resplandores de aurora.

Sé que tus manos leves no estrecharán las mías, ni probarán mis labios lo dulce de tu boca; que por el lago azul de mis melancolías no pasará tu blanco esquife de reina loca.

Y, sin embargo, te amo desesperadamente, y, como un ciego, voy tras tus amadas huellas; 
o elevo mis canciones, como un niño demente que alza las manos para alcanzar las estrellas. (Silva 151)

Efectivamente, este poema no presenta referencias a ninguna realidad social concreta, y podría haber sido escrito, teóricamente, por cualquier otro poeta familiarizado con algunos elementos de la estética modernista: el lago de las melancolías de la voz poética, por ejemplo, tiene que ser "azul"; las flores deshojadas por el sujeto enamorada tienen que ser "lirios"; la oscuridad de la noche y la claridad de la aurora deben ser contrastadas en una construcción bipolar; y, muy "escapistamente", la destinataria de las divagaciones tiene que ser elevada al rango aristocrático europeizante y completamente ajeno al Ecuador republicano de "princesa". No obstante, la asunción axiomática de la voz de que su objeto de deseo está tan lejano como las estrellas, y de que sus manos nunca se estrecharán, adquiere algo de demasiado definitivo cuando se la piensa más detenidamente. Sin lugar a dudas, ese pesimismo y ese regodeo en la autocompasión y en un sino trágico es característica de la parte más propiamente romántica del modernismo hispanoamericano (aquella en la que la figura de un Werther es muy influyente). Pero, ¿no se podría leer aquí, además, una aceptación de un sujeto marginal, marcado como pobre y como "cholo" o "moreno", del hecho cierto de que, haga lo que haga, y muy especialmente en lo que respecta a la consumación de su deseo amoroso/sexual, jamás podrá cruzar determinadas líneas raciales y sociales imperantes en su medio?

De hecho, hay ocasiones en las que Silva llega incluso a tematizar su propia actitud enajenada —o escapista - y su persistencia en el silencio para, sin llegar a explicar dicha actitud o dicha persistencia, sí insinuar que ambas están motivadas por causas mucho más profundas, pero también mucho más innombrables, que la adopción de un simple gesto modernista de moda o que un mero no querer afrontar la realidad. En el poema decimotercero de su colección La fuente triste, incluida en la selección de poesías de Silva que Gonzalo Zaldumbide publicara en 1926, por ejemplo, se lee lo siguiente: 
La enfermedad que yo tengo

mi corazón sólo sabe:

como él nunca la dirá,

nunca ha de saberla nadie.

La sabe el claro de luna

y el parque gris: ¡preguntadles!...

La sabe el viento que pulsa

las liras crepusculares...

Mis versos la están diciendo

y no la comprende nadie...

La enfermedad que yo tengo

en silencio ha de matarme. (Silva 323)

Más allá de la parafernalia modernista presente también en este poema (el uso del término "enfermedad" para definir un estado de ánimo o una sensibilidad específica, la alusión a "las liras crepusculares", el final de tintes trágicos, etc.), en la primera estrofa la voz poética está provocando conscientemente a quien la lea, afirmando sin ambages ("nunca ha de saberla nadie") que no le dará gusto y que se llevará a la tumba la razón última de ese sufrimiento que tan performativamente ha desplegado a lo largo de innumerables poemas y que es catalogado de afectado o de ajeno a la realidad y de escapista por la crítica. Más significativamente, si cabe, en la tercera estrofa la voz asegura incluso que la razón ya está dicha, que siempre ha estado dicha, pero que nadie ha sido capaz de comprenderla, ya sea porque nadie está en las alturas etéreas del genio romántico, porque, más prosaicamente, nadie se ha dado el trabajo de leer los versos como se 
debe, o porque la "enfermedad" en sí es no sólo grave e incurable sino también, y a un nivel fundamental, incomprensible, innombrable.

No parece descabellado leer estos versos, entonces, como unos que recogen un momento en el que el poeta llega al límite de lo decible en un lenguaje poético específico (el del modernismo) y en su calidad de sujeto marginal en la periferia. En estas condiciones, decir que Silva es simplemente escapista, en el sentido negativo del término, es claramente injusto, dado que el texto expresa tanto una angustia como una experiencia de vacío provocadas por realidades concretas que son, finalmente, innombrables. Más aún, pedirle a Silva que salte al otro lado del límite al que ha arribado, y que se desnude más de lo que ya lo hace, por así decirlo, es pedirle que se eleve por encima de las contradicciones de las que nace, sin embargo, su poesía. Aparte de que es imposible salirse del discurso que lo constituye a uno, ¿no sería este elevarse por encima de las contradicciones justamente "escapar" al mundo en lugar de confrontarlo?

\section{Bosquejo de conclusión}

A lo largo de este ensayo se ha intentado construir a Medardo Ángel Silva, en resumen, como un autor marginal en un contexto de modernidad periférica, enfrentado a las contradicciones y a las tensiones que dicha posición quizás necesariamente conllevan. Además, se ha intentado ver que la autonegación de la propia identidad, así como la estrategia de una creación de una identidad artificial propia por medio de la escritura, están presentes tanto en los poemas aparentemente superficiales y meramente románticos como en las crónicas urbanas de Silva, que durante décadas estuvieron esperando a que una lectura más allá de los lugares comunes del escapismo y del preciosismo superfluo les diera un lugar como documentos del shock ante una modernidad mediocre, y ante un desarrollo trágicamente desigual y combinado, de un sujeto no solamente sensible, sino también encadenado por su raza y por su posición social a la periferia de la periferia. 
Así, en el cortísimo segundo poema de La fuente triste, Silva se queja abiertamente, por medio de su voz poética, del encasillamiento como escapista del que ya en vida es víctima:

Dices que no tienen motivo mis penas

pues las lloro mías cuando son ajenas...

¡Ay! Ese es mi encanto:

llorar por aquellos que no vierten llanto (Silva 312)

¿Por quién llora Silva, aquí? Por un lado, el hipotético lector del poema ${ }^{10}$ asegura que, como el epígono escapista que supone que el poeta es, éste llora por penas "ajenas", o sea no propias de su realidad, prestadas, irrelevantes. Ahora bien, la voz poética no niega de plano dicha acusación, en el sentido de que nunca dice que las penas le pertenecen también. Significativamente, sin embargo, tampoco la confirma. Guarda silencio, en efecto, sobre si las "penas" así llamadas "ajenas" son realmente suyas o no. Lo único que deja claro, como para que no existan dudas al respecto, es que llora "por aquellos que no vierten llanto", como una voz que habla por aquellos que no tienen voz. Como un sujeto marginal, en otras palabras, que puede llorar en el concierto modernista y dejar impresa su huella, pero sólo a costa de no nombrar su marginalidad y, de hecho, de negarla obsesivamente, en una tensión que, a posteriori, parece evidente que acabaría mal.

“[E]nfermo de lecturas", en efecto, “y perfectamente inútil”, como el alter ego que Silva contempla en su crónica sobre el cine sin poder jamás nombrar finalmente la "enfermedad", el poeta es incapaz de resolver las contradicciones sin las que, como modernista, no puede ser, y decide permitir que el "muchacho" se mate. Naturalmente, el hecho de que casi exactamente un mes después de la

\footnotetext{
${ }^{10}$ Uso aquí, conscientemente, la forma masculina (“el lector”), ya que el poema no parece dirigirse a un sujeto lector cualquiera sino más específicamente a una persona dedicada a la actividad de la crítica literaria, la cual estaba, en el Ecuador de principios del siglo XX, prácticamente reservada a los hombres.
} 
publicación de esta crónica (el 11 de junio del mismo año) la cosa haya acabado "mal" y el autor se haya dado un disparo en la cabeza enfrente de su pretendida, Amada Villegas, dando lugar a una leyenda que no ha parado de crecer, desde entonces, y que lo ha convertido en un elemento importante de la identidad ecuatoriana y más específicamente guayaquileña, no hace más que subrayar el que, lejos de haber estado de espaldas a la realidad, los comentarios periodísticos de Silva, así como los significativos silencios de su poesía, son testimonios, y testimonios relevantes como el mismo modernismo todo, de una realidad contradictoria y brutal

\section{Bibliografía}

Balseca, Fernando. "El niño poeta de Guayaquil". En Medardo Ángel Silva: Obras completas. Melvin Hoyos Galarza y Javier Vásconez (ed.). Guayaquil: Biblioteca Municipal, 2004, pp. 13-24.

. Llenaba todo de poesía: Medardo Ángel Silva y la modernidad. Quito: Taurus, 2009.

Benavides, O. Hugo. The Politics of Sentiment. Imagining and Remembering Guayaquil. Austin: University of Texas Press, 2006.

Benjamin, Walter. Charles Baudelaire. Ein Lyriker im Zeitalter des Hochkapitalismus. En Abhandlungen. Gesammelte Schriften. Band I- 2. Francfort: Suhrkamp, 1974, pp. 509-690.

Butler, Judith. Bodies that Matter. On the Discursive Limits of "Sex". Nueva York: Routledge, 1993. 
CATEDRAL Tomada: Revista de crítica literaria latinoamericana / Journal of Latin American Literary Criticism Escapismo de sí mismo: Medardo Ángel Silva como poeta marginal y la autonegación de la identidad.

Campaña Avilés, Mario. "Estudio Introductorio”. En La Generación Decapitada: Silva, Fierro, Borja y otros. Quito: Libresa, 1991, pp. 9-36.

Cueva, Agustín. Lecturas y rupturas: Diez ensayos sociológicos sobre la literatura del Ecuador. Quito: Planeta, 1986.

Egüez, Iván. Pájara la memoria. Quito: Libresa, 1995 (primera edición 1985).

Espinosa Cordero, Simón. Grandes escritores de la Patria. Suplemento especial de Vistazo, Guayaquil, sin fecha, 2004.

Fernández, María del Carmen. El realismo abierto de Pablo Palacio. En la encrucijada de los 30. Quito: Libri Mundi, 1991.

Holst, Gilda. "Medardo Ángel Silva”. En Diccionario Enciclopédico de las Letras de América Latina. Tomo III. Nelson Osorio (ed.). Caracas: Biblioteca Ayacucho y Monte Ávila Editores, 1995, pp. 4481-4482.

Lasarte Valcárcel, Javier. "Pueblo y mujer: Figuraciones dispares del intelectual modernista (Martí y González Prada”. En Delmira Agustini y el modernismo: Nuevas propuestas de género. Tina Escaja (comp.). Rosario: Beatriz Viterbo Editora, 2000, pp. 38-54.

Manzoni, Celina. El mordisco imaginario. Crítica de la crítica de Pablo Palacio. Buenos Aires: Biblos, 1994.

Mussó, Luis Carlos. “A la sombra de la palabra”. En Medardo Ángel Silva: Obras completas. Melvin Hoyos Galarza y Javier Vásconez (ed.). Guayaquil: Biblioteca Municipal, 2004, pp. 25-37.

Pareja Diezcanseco, Alfredo. "Prólogo". En José de la Cuadra: Obras completas. Jorge Enrique Adoum (comp.). Quito: Casa de la Cultura, 1958.

Silva, Erika. Los mitos de la ecuatorianidad: ensayo sobre la identidad nacional. Quito: Abya-Yala, 1992.

Silva, Medardo Ángel. Obras completas. Melvin Hoyos Galarza y Javier Vásconez (ed.). Guayaquil: Biblioteca Municipal, 2004. 
Vallejo, Raúl. "Medardo Ángel Silva y la crónica de una época de artificios". En Medardo Ángel Silva: Obras completas. Melvin Hoyos Galarza y Javier Vásconez (ed.). Guayaquil: Biblioteca Municipal, 2004, pp. 461-486. 